\title{
PENGGUNAAN MS-222 (TRICAINE) UNTUK PEMBIUSAN BANDENG (Chanos chanos) UMPAN
}

\author{
Rohama Daud $^{*}$, Suwardi ${ }^{*}$, M.J. Yacob ${ }^{*}$ dan Utojo $\left.{ }^{*}\right)$
}

\begin{abstract}
ABSTRAK
Kendala yang sering dihadapi dalam penyediaan umpan hidup untuk penangkapan ikan tuna/cakalang adalah masih tingginya kematian umpan dalam transportasi menuju daerah penangkapan, sehingga diperlukan pembiusan umpan sebelum diangkut.

Penelitian ini dilakukan untuk mengetahui dosis tricaine (MS-222) yang aman dan lama sedatasi bandeng umpan hidup yang layak digunakan selama pengangkutan. Lima tingkatan dosis yang digunakan untuk pembiusan yaitu 20, 30, 40, 50, dan 60 ppm dengan 3 kali ulangan. Wadah pengangkutan berupa kantong plastik dengan ukuran 80 X $40 \mathrm{~cm}^{2}$, diisi air dengan volume $5 \mathrm{~L}$, kemudian dimasukkan oksigen murni sebanyak $2 \mathrm{x}$ volume air, lalu diikat. Kepadatan ikan 10 ekor/kantong.
\end{abstract}

Hasil penelitian menunjukkan bahwa dosis 40 dan 50 ppm menghasilkan waktu induksi yang relatif singkat (2,0 dan 1,67 menit), durasi sedatasi yang lama (296 dan 332 menit), serta sintasan yang tinggi $(100 \%)$.

\section{ABSTRACT: The use of MS-222 (tricaine) for the anaesthetion of milk fish (Chanos chanos) used for life bait. By: Rohama Daud, Suwardi, M.J. Yacob and Utojo.}

One of the crucial problems in the life bait supply for tuna capture is the high mortality of the bait during transportation to fishing ground. Thus anaestation of life bait during the handling of the fish before transportation is necessary.

This experiment was conducted to find the effective dosage of tricaine for the sedation of milkfish used for life bait during transportation. Five anaesthetic dosages were used; i.e. 20, 30, 40, 50, and $60 \mathrm{ppm}$ with three replications. Size and weight of milkfish were $15-17 \mathrm{~cm}$ and $55-60 \mathrm{~g}$ respectively. Plastic bags were filled with $5 \mathrm{~L}$ of pond water, $10 \mathrm{~L}$ of pure oxygen and $10 \mathrm{fish} / \mathrm{bag}$.

The result showed that dosages of 40 and $50 \mathrm{ppm}$ had shorter induction time (2.0 and 1.67 minutes), longer sedation time (296 and 332 minutes), and higher survival rates (100\%).

KEYWORDS: MS-222(tricaine); anaesthetic; life bait; milkfish.

\section{PENDAHULUAN}

Transportasi ikan hidup saat ini kian berkembang, baik untuk penelitian ataupun untuk keperluan bisnis seperti ekspor ikan hidup yang terus meningkat, serta untuk keperluan transportasi umpan penangkapan tuna dan cakalang di laut. Meningkatnya permintaan ikan tuna dalam pasar internasional akan merangsang tumbuhnya budidaya bandeng yang secara tidak langsung akan memproduksi umpan hidup (Ahmad, 1993). Rumahpute et al. (1987) menyatakan bahwa ketersediaan umpan hidup telah menjadi salah satu faktor pembatas dominan dalam kegiatan penangkapan ikan tuna dan cakalang di beberapa wilayah Indonesia. Satu di antara jenis ikan umpan untuk penangkapan ikan tuna dan cakalang dengan alat tangkap rawai selain ikan layang, lemuru dan kembung adalah ikan bandeng (Chanos chanos). Keunggulan yang dimiliki ikan bandeng sebagai umpan hidup adalah mudah diperoleh dalam jumlah besar, benih tersedia untuk budidaya, tahan terhadap penyakit dan kesegarannya dapat dipertahankan (Cholik dan Pasaribu, 1989).

\footnotetext{
*) Peneliti pada Balai Penelitian Perikanan Pantai, Maros
} 
Kendala yang sering dijumpai dalam penyediaan umpan agar tetap hidup untuk sampai di daerah penangkapan, yaitu tingginya kematian selama menuju daerah penangkapan. Penyebab kematian di antaranya adalah akibat stres dan kerusakan fisik karena kesalahan penanganan (Carrasco et al., 1984). Untuk mengatasi hal tersebut, transportasi umpan hidup ke daerah penangkapan dapat dilakukan dengan jalan pembiusan. Obat bius merupakan senyawa kimia yang dapat menyebabkan hilangnya seluruh atau sebagian rasa pada seluruh tubuh sebagai akibat dari penurunan fungsi syaraf sehingga menghalangi aksi dan hantaran impuls syaraf (Bose et al., 1991). Selanjutnya dikatakan bahwa obat bius bila dilarutkan dalam air akan mengurangi laju respirasi dan aktivitas ikan. Berbagai bahan kimia telah digunakan sebagai obat bius dalam perikanan, khususnya pada penanganan induk, penanganan sampel, penandaan (Siwicki, 1984) dan transportasi (Burhanuddin et al., 1989; Suparno dan Irianto, 1995).

Seiring dengan meningkatnya permintaan ikan hidup terutama untuk umpan, penggunaan bahan kimia sebagai obat bius makin diperlukan. Hal yang perlu diperhatikan adalah senyawa kimia tersebut tidak bersifat racun terhadap ikan yang dapat menimbulkan efek bius yang cukup lama dengan dosis yang sangat rendah, mudah didapat dan harganya terjangkau (Schreck and Moyle, 1990). Salah satu jenis obat bius yang digunakan untuk mengurangi stres dan kematian pada saat penanganan ikan adalah MS-222 atau tricaine methasulfonate (Bourne, 1984 dan Subasinghe, 1997). Rumus kimia tricaine (MS-222) adalah $\mathrm{C}_{9} \mathrm{H}_{11} \mathrm{O}_{2} \mathrm{~N}+\mathrm{CH}_{3} \mathrm{SO}_{3} \mathrm{H}$.

MS-222 adalah bahan anestetika yang digunakan sebagai obat bius pada transportasi ikan yang terbius sementara, sehingga tidak peka terhadap getaran, mudah penanganannya, waktu induksi cepat serta tidak menimbulkan dampak negatif terhadap ikan dan manusia pada dosis tertentu. Menurut Bourne (1984), mutu MS-222 ditentukan oleh aminobenzenzoate yang memiliki sifat membius, melepaskan uap serta dapat memberikan bau yang tajam dalam air yang sifatnya menyengat. Walaupun telah digunakan pada berbagai jenis ikan, tetapi belum ada informasi tentang pembiusan bandeng umpan. Penelitian ini bertujuan untuk mengetahui dosis MS-222 (tricaine) dan lama sedatasi yang diperlukan dalam pembiusan bandeng umpan yang aman selama pengangkutan.

\section{BAHAN DAN METODE}

Penelitian dilakukan di Laboratorium Basah Instalasi Tambak Percobaan Maranak pada bulan Oktober 1996. Bandeng umpan diperoleh dari tambak Maranak, dengan ukuran panjang dan bobot masing-masing $15-17 \mathrm{~cm}$ dan $60-67 \mathrm{~g}$. Obat bius yang digunakan adalah MS-222 dengan nama lain tricaine methane sulfonat, berbentuk bubuk kristal putih yang halus. Pada uji pendahuluan dilakukan penentuan dosis letal MS-222 untuk bandeng umpan dengan konsentrasi 10, 50, 100, 150 dan $200 \mathrm{ppm}$. Setelah diketahui dosis letal (>50 ppm), percobaan dilanjutkan dengan uji konsentrasi untuk membius ikan. Rancangan percobaan acak lengkap dengan perlakuan dosis MS-222 yang dicobakan adalah 20,30, 40, 50 dan 60 ppm dengan 3 kali ulangan. Analisis data dilakukan dengan sidik ragam dan dilanjutkan dengan uji BNT. Kepadatan ikan yang digunakan adalah 10 ekor/5 L. Sebagai wadah percobaan digunakan kantong plastik berukuran $80 \times 50 \mathrm{~cm}^{2}$. Tiap-tiap kantong diisi 5 $\mathrm{L}$ air bersalinitas $15 \mathrm{ppm}$ dan gas oksigen dengan perbandingan 1:3 (Bocek, 1992), kemudian diikat.

Peubah yang diamati adalah waktu induksi, dan lama ikan sedatasi (waktu pemulihan sampai ikan sadar kembali). Ikan pingsan ditandai dengan posisi ikan yang miring atau terlentang, tidak berenang di dasar dan permukaan kantong dengan operculum (tutup insang) tetap bergerak. Peubah kualitas air sebagai salah satu faktor yang turut menentukan sintasan ikan diamati pada awal dan akhir penelitian (saat ikan siuman) meliputi oksigen terlarut, $\mathrm{CO}_{2}$ bebas, amoniak, suhu, dan $\mathrm{pH}$, dan dianalisis secara deskriptif.

\section{HASIL DAN PEMBAHASAN}

Ikan uji yang dimasukkan ke dalam air yang telah diberi MS-222 (tricaine), pertama akan tenang di dasar selama beberapa detik, kemudian pergerakan tutup insang yang semakin cepat dan kemudian bergerak ke permukaan dengan gerakan tidak teratur, selanjutnya badan terbalik yang diikuti oleh pergerakan sirip yang semakin lamban dan akhirnya ikan akan terlentang di dasar atau di permukaan. Hal yang demikian 
terjadi pada semua perlakuan. Dalam keadaan seperti ini ikan tidak bergerak, tetapi tutup insang tetap bergerak.

Hasil pengamatan konsentrasi MS-222 terhadap waktu induksi, waktu pemulihan dan sintasan bandeng umpan disajikan pada Tabel 1 . Ada kecenderungan bahwa semakin tinggi dosis obat bius yang digunakan, menghasilkan waktu induksi yang makin relatif singkat. Uji statistik dengan sidik ragam menunjukkan dosis obat bius ber-pengaruh sangat nyata terhadap waktu induksi obat pada ikan uji $(\mathrm{P}<0,01)$. Uji lanjut BNT menunjukkan bahwa perlakuan dosis 20 ppm mempunyai waktu induksi yang paling lambat $(\mathrm{P}<0,05)$ dibandingkan dengan dosis 30 . 40, 50 dan $60 \mathrm{ppm}$. Waktu induksi pada dosis 30 ppm lebih lambat $(\mathrm{P}<0,05)$ dari dosis 40,50 dan $60 \mathrm{ppm}$, sedang dosis 40, 50 dan $60 \mathrm{ppm}$ mempunyai waktu induksi yang sama $(\mathrm{P}>0,05)$ terhadap obat bius MS-222. Menurut Siwicki (1984), dalam anestasi diharapkan waktu untuk induksi relatif cepat tetapi juga mengurangi stres pada ikan. Selanjutnya Schreck dan Moyle (1990) menerang-kan bahwa obat bius yang baik harus mempunyai karakteristik seperti berikut: waktu induksi kurang dari 15 menit (lebih baik lagi jika kurang dari 3 menit), cepat dieksresi, dan waktu pemulihan yang singkat.

Tabel 1. Hasil anestesi bandeng umpan dengan menggunakan MS-222.

Table 1. Results of the anaesthetion of life bait milk fish by MS-222.

\begin{tabular}{|c|c|c|c|c|}
\hline $\begin{array}{c}\text { Dosis } \\
\text { Dosage } \\
\text { (ppm) }\end{array}$ & $\begin{array}{l}\text { Perlakuan } \\
\text { Treatment }\end{array}$ & $\begin{array}{l}\text { Waktu induksi } \\
\text { Induction time } \\
\text { (mnt) }\end{array}$ & $\begin{array}{c}\text { Durasi sedatif } \\
\text { Sedative duration } \\
\text { (mnt) }\end{array}$ & $\begin{array}{c}\text { Tingkat sintasan } \\
\text { SR } \\
(\%) \\
\end{array}$ \\
\hline \multirow[t]{4}{*}{20} & 1 & 9 & 153 & 100 \\
\hline & 2 & 7 & 171 & 100 \\
\hline & 3 & 7 & 162 & 100 \\
\hline & rata-rata (mean) & $7.67^{\mathrm{a}}$ & $162^{\mathrm{a}}$ & 100 \\
\hline \multirow[t]{4}{*}{30} & 1 & 6 & 260 & 100 \\
\hline & 2 & 5 & 257 & 100 \\
\hline & 3 & 4 & 251 & 100 \\
\hline & rata-rata (mean) & $5^{b}$ & $256^{\mathrm{b}}$ & 100 \\
\hline \multirow[t]{4}{*}{40} & 1 & 2 & 294 & 100 \\
\hline & 2 & 2 & 300 & 100 \\
\hline & 3 & 2 & 294 & 100 \\
\hline & rata-rata (mean) & $2^{c}$ & $296^{\mathrm{b}}$ & 100 \\
\hline \multirow[t]{4}{*}{50} & 1 & 2 & 327 & 100 \\
\hline & 2 & 2 & 330 & 100 \\
\hline & 3 & 1 & 339 & 100 \\
\hline & rata-rata (mean) & $1.67^{\mathrm{C}}$ & $332^{\mathrm{bc}}$ & 100 \\
\hline \multirow[t]{4}{*}{60} & 1 & 1 & 343 & 0 \\
\hline & 2 & 1 & 338 & 0 \\
\hline & 3 & 1 & 339 & 0 \\
\hline & rata-rata (mean) & $1^{\prime \prime}$ & $340^{c}$ & 0 \\
\hline
\end{tabular}

Nilai rata-rata dalam kolom yang sama diikuti huruf yang sama menunjukkan tidak berbeda nyata ( $>0,05)$; Averages in the same column with the same supercript indicate no significant differences $(P>0.05)$ 
Pemulihan bervariasi menurut dosis obat bius yang digunakan. Makin tinggi konsentrasi obat bius makin cepat waktu induksi dan makin lama durasi pingsan pada ikan uji. Pada konsentrasi 50 dan $60 \mathrm{ppm}$, waktu induksi relatif cepat dan durasi pingsan bertambah lama, tetapi untuk mencapai pulih kembali (sehat dan bugar) ikanikan harus dikondisikan dalam lingkungan baik dan diaerasi selama minimal 15 menit. Pada dosis 20-40 ppm, ikan-ikan uji pada saat bangun dari pingsan kelihatan bugar sekali, sehingga dapat ditebar langsung di penampungan. Uji lanjut dengan BNT memperlihatkan bahwa dosis 20 ppm mempunyai lama pingsan yang lebih singkat $(\mathrm{P}<0,05)$ dibanding dengan perlakuan lainnya. Perlakuan dosis 30 ppm mempunyai waktu lama pingsan yang relatif sama $(P>0,05)$ dengan perlakuan dosis 40 dan $50 \mathrm{ppm}$, tetapi lebih singkat $(\mathrm{P}<0,05)$ dibanding dengan perlakuan dosis 60 ppm, sedangkan dosis 50 dan 60 ppm mempunyai waktu yang relatif sama $(\mathrm{P}>0,05)$. Menurut Subasinghe (1977) apabila ikan yang diangkut menggunakan MS-222 diperlukan untuk konsumsi, sebaiknya dipelihara selama 30 hari setelah perlakuan agar residu obat bius yang dapat mengakibatkan keracunan dapat terurai.

Peubah kualitas air yang diamati selama pengangkutan disajikan pada Tabel 2. Peubah kualitas air berubah seiring dengan lamanya ikan pingsan. Semakin tinggi dosis obat bius yang digunakan menyebabkan semakin lama ikan pingsan, sehingga penurunan oksigen semakin tinggi yang mengakibatkan kandungan oksigen yang terlarut semakin rendah. Perubahan kualitas air selama pengangkutan dapat diakibatkan oleh penambahan obat bius (Bourne, 1984) dan aktivitas ikan selama diangkut (Clucal dan Ward, 1996). Belum diketahui apakah pengurangan oksigen ini akibat dari peningkatan dosis obat bius atau pengaruh lamanya ikan pingsan. Bose (1991) mengemukakan bahwa adanya obat bius dalam air media dapat mengurangi proses respirasi dan aktivitas ikan, namun Clucal dan Ward (1996) menyatakan bahwa ikan mempunyai salah satu kebutuhan pokok yaitu proses pernapasan tetap berlangsung.

Temperatur air media pengangkutan nampak meningkat pada dosis obat bius $40 \mathrm{ppm}$. Menurut Bocek (1992) kebutuhan respirasi ikan lebih besar pada suhu yang lebih tinggi, seperti terlihat pada Tabel 2. Semakin tinggi dosis obat bius yang digunakan semakin tinggi pula temperatur air media selama pengangkutan yang kemungkinan diakibatkan oleh lamanya waktu sedatasi (pembiusan).

Penurunan $\mathrm{pH}$ media selama pengangkutan dapat diakibatkan oleh penambahan obat bius dan hasil eskresi ikan uji. Semakin lama waktu transportasi ikan, semakin rendah nilai $\mathrm{pH}$ pada air media. Hal ini dinyatakan oleh Bourne (1984) bahwa salah satu masalah yang dihadapi dalam pembiusan ikan adalah menurunnya $\mathrm{pH}$ pada saat penambahan obat-obatan.

Tabel 2. Kualitas air media pengangkutan dengan menggunakan MS-222.

Table 2. Water quality of transport medium with the use of MS-222.

\begin{tabular}{cccccc}
\hline $\begin{array}{c}\text { Dosis } \\
\text { Dosage } \\
(\mathbf{p p m})\end{array}$ & $\begin{array}{c}\text { Oksigen terlarut } \\
\mathbf{D O}\end{array}$ & $\begin{array}{c}\mathbf{C O}_{2} \\
(\mathbf{p p m})\end{array}$ & $\begin{array}{c}\mathbf{N H}_{\mathbf{4}} \\
(\mathbf{p p m})\end{array}$ & $\begin{array}{c}\text { Suhu } \\
(\mathbf{p p m})\end{array}$ & $\begin{array}{c}\text { Temperature } \\
\left({ }^{\mathbf{O}} \mathbf{C}\right)\end{array}$ \\
\hline $0^{*}$ & 5.6 & 0 & 0.0084 & 28.2 & 8.0 \\
$20^{* *}$ & 4.4 & 53.27 & 0.0479 & 28.2 & 6.5 \\
$30^{* *}$ & 4.3 & 67.92 & 0.0496 & 28.2 & 6.5 \\
$40^{* *}$ & 3.9 & 45.28 & 0.0753 & 28.5 & 6.3 \\
$50^{* *}$ & 2.7 & 41.29 & 0.0697 & 28.9 & 6.3 \\
$60^{* *}$ & 2.1 & 50.60 & 0.0741 & 28.9 & 6.0 \\
\hline
\end{tabular}

\footnotetext{
* = sebelum pengangkutan (before transportation)
}

** = sesudah pengangkutan (after transportation) 
Akibat lain dari hasil eksresi, yaitu meningkatnya kandungan amoniak dalam media seiring dengan lamanya waktu pengangkutan. Hal ini dapat mempengaruhi sintasan ikan.

\section{KESIMPULAN DAN SARAN}

Dosis MS-222 (tricaine) 50 dan 40 ppm dapat dianjurkan untuk digunakan sebagai obat bius pada transportasi bandeng umpan ukuran panjang dan bobot masing-masing $15-15 \mathrm{~cm}$ dan 55-60 g, karena mempunyai waktu induksi lebih cepat (2-1,67 menit) dan waktu pembiusan (sedation time) lebih lama (296-332 menit).

\section{DAFTAR PUSTAKA}

Ahmad, T. 1993. Support of research on milkfish (Chanos chanos Forskal) for fishery development. Indonesian Agriculture Research \& Development Journal. 15 (1): 10-13.

Bocek, A. 1992. Pengangkutan ikan. Pedoman teknis. Proyek Penelitian dan Pengembangan Perikanan. Pusat Penelitian dan Pengembangan Perikanan. Jakarta. 17 hal.

Bose, A.N., S.N. Ghosh., C.T. Yang., and A. Mitra. 1991. Coastal aquaculture engineering. Edward Arnold. A division of hodder \& stoughton, London. $375 \mathrm{pp}$.

Bourne, P.K. 1984. The use of MS-222 (tricaine metane sulphonate) as an anaesthetic for routine blood sampling in three species of marine Teleostei. Aquaculture, 36:313-321.
Burhanuddin. Sulaiman dan T. Wikanta. 1989. Minyak cengkeh sebagai obat bius untuk ikan beronang (Siganus guttatus). J.Penelitian, 5(1). $61-65$.

Carrasco, S., H. Sumano, and R. Navarro - Fierro. 1984. The use of lidocaine-sodium bicarbonate as anaesthetic in fish. Aquaculture, 41:395-398.

Cholik, F dan A. Pasaribu. 1989. Budidaya bandeng umpan, prospek dan permasalannya. Balai Penelitian Budidaya Pantai, Maros. 15 hal.

Clucal, I.J and A.R. Ward. 1996. Post-harvest fisheries development: A guide to handling, preservation, processing and quality. Chatham Maritime, Kent ME-4, United Kingdom, NRI.

Rumahpute, B., M. Syukur., dan J. Latelay. 1987. Survey kualitas ikan umpan yang baik dalam menunjang perikanan cakalang di perairan Maluku Tengah. Jurnal Penelitian Perikanan Laut, (43): 75-80.

Schreck, C.B and Moyle. 1990. Methods for fish biology. American Fisheries Society. Bathesda, Mayland USA. 684 pp.

Siwicki, A. 1984. New anaesthetic for fish. Aquaculture, 38:171-176.

Subasinghe, S. 1997. Live fish-handling and transportation. Infofish International, 2:39-43.

Suparno dan H.E. Irianto. 1995. Transportasi ikan hidup dan teknologi pasca panen. Prosiding temu usaha pemasyarakatan teknologi keramba jaring apung bagi budidaya laut. Jakarta 12.13 April 1995. Badan Penelitian dan Pengembangan Pertanian. Hal 88-106. 